\title{
Knowledge, Attitude and Practice of Family Planning Among the Currently Married Women of Reproductive Age of Shivasatakshi Municipality Jhapa District, Nepal
}

- Sarita Bista

\begin{abstract}
This study examines the Knowledge, Attitude and Practice of Family Planning among the Currently Married Women of Reproductive Age (15-49 Years); a case study of Shivasatakshi Municipaity Jhapa district is based on primary data successfully collected from sample survey, covering 100 sample respondents ` from 100 sample households. The main objective of the study is to fine out the knowledge, attitude and practice of family planning methods among currently married women of reproductive age group (15-49 years) and the specific objective of the study are to study the socioeconomic and demographic determinants of currently use of family planning method and to identify the reason the reason for use and non-use of family planning. Out of 100 sample respondents 83 percent women are literate and 17 percent are illiterate. The major occupations of the respondents are agriculture and services. Among currently married women, 99 percent of respondents are found to be familiar with at least one family planning method. Out of total respondents, 91 percents are ever uses and 92 percent are currently using family planning methods. There is strongly positive relationship existed between use of family planning method and socio-economic and demographic variables like educational status of women and number pf living children. Easily accessible and no side effect are main reasons for using family planning method. Desire for and husband and family's disagreement are most important reason for not using family planning method.
\end{abstract}

Key Words: Knowledge, attitude, practice, family planning and contraceptive method

\section{Introduction}

The family planning in Nepal is started with the established of family planning association of Nepal in 1959. In fact, Nepal was one oft the first countries of South Asia where information about family planning is available through a non government program. Since 1968 Government of Nepal has been actively involved in providing family planning services with the establishment of Nepal Family Planning and Maternal Child Health Project. Initially family planning was intergrated with maternal child health services(CBS,2014).

Nepal is a landlocked country inhibited by Multilanguage, multi religion and multi ethnic. Population of Nepal is 26,494,504. The total population Shivasatakshi Municipaity Jhapa is 39,689. If the population increases in the same ratio it will double within 31 years (CBS, 
2011). The main cause to increase the population growth is continuous decline in death rate and low level of family planning methods use.

Population growth is one of the serious problems in many developing countries. Nepal is also not free from this very problems, Nepal is facing the problem of attaining sustainable declination in fertility to reduce population burden. In spite of increased level of investment in population field during the five successive development plans, decline in level of fertility remained very low. To avoid such s catastrophic situation, the government of Nepal is making every effort to promote family planning practices.

Actually the population of the country gets increased either due to high birth rate or due to high immigrants. The major cause of population increase in Nepal is natural phenomena i.e. birth. Total fertility rate is 4.5 per women which is quite excessive expect some African countries. The trend of high fertility is observed in Nepal which is because of early marriage early conception and lack of contraceptive knowledge and its use (2001, CBS).

Knowledge of contraception is universal in Nepal. One in two currently married women is using a method of contraception, with most women using a modern method (43 percent). The three most popular modern methods used by married women are female sterilization (15 percent), injectables ( 9 percent), and male sterilization (8 percent). Use of modern methods has increased by 66 percent in the past 15 years. However, there has been little change in the last five years. The government sector remains the major provider of contraceptive methods, catering to more than two in three users (69 percent). Overall, 51 percent of contraceptive users discontinued using a method within 12 months of starting its use. Twenty-six percent of episodes of discontinuation occurred because the woman's husband was away. Twenty-seven percent of currently married women have an unmet need for family planning services, with 10 percent having an unmet need for spacing and 17 percent having an unmet need for limiting (MoHP, 2011).

Overall, 53\% of currently married women use a method of family planning, with $43 \%$ using a modern method and $10 \%$ using a traditional method. Female sterilization is the most commonly used method (15\%), followed by injectables (9\%), male sterilization (6\%), and the pill (5\%). Only 15\% of currently married women age 15-19 use a modern method of contraception. Three out of every five women who began using a contraceptive method in the 5 years before the survey discontinued the method within 12 months. The most common reason for discontinuing a method is the husband being away (47\%), followed by side effects or health concerns (18\%) and the desire to become pregnant (13\%). Twenty-four percent of married women of reproductive age have an unmet need for family planning; that is, they want to space or limit births but are not using contraception (MoHP, 2016). 
This study found out the general outlook or attitude and awareness of family planning programs, the level of knowledge and practices of family planning methods in the villager of Shivasatakshi Municipaity Jhapa district. The study tries to locate hindrances, if any towards the success of family planning programs in the area.

\section{Objectives}

The main objective of this study is to examine the reasons for use and non-use of family planning services. The specific objectives of the study are the socio-economic and demographic determinants of currently use of family planning method.

\section{Methodology}

The present study has conducted among currently married women aged 15 to 49 years' resident in different three wards of Shivasatakshi Municipaity Jhapa district. Descriptive analysis is used in this study. This study tends to find out the knowledge, attitude and practice of family planning methods in Shivasatakshi Municipaity Jhapa district. This study was based on descriptive as well as exploratory research design which may consider as an appropriate and best for the analysis of this type of research work. This study was exploratory because it makes attempt to explore the process of study area. To carry out the study 100 household/respondent was taken. One household one woman aged 15 and above was interviewed among the total households. The study was conducted by using simple random sampling because the population size was small. First of all, the household was coded was mixed and shake well than desirable numbers, i.e. 100 households were selected by using lottery method with in the three ward of this municipality.

This study was based on both primary and secondary data. Primary data are collected by field visit in the study area. Secondary sources are published and unpublished reports, research studies and articles by different researchers, line agencies, governmental and non-governmental organizations. Questionnaire, interview and observation were used to draw required data, quantitative as well as qualitative. In the beginning, a pilot study was conducted. The pilot survey was conducted in ten households of the study area and the survey proved that the questionnaire required no major modifications. In order to obtain core data, the researcher interviewed individual respondents in the study area. It took almost one month to collect data from all the households. As it became clear to the respondents that the study was mainly for the academic purpose and the information regarding individuals name was kept confidentially, they began to feel assured answer the questions. The data collected from the field were manually tabulated and analyzed. Simple and descriptive statistics such as frequency counts, percentages were used whenever it was felt necessary to explain the overall findings. For qualitative analysis, it represents the personal feeling an experience will tend to present in the sentence. 


\section{Results}

\subsection{Age and Age at Marriage of respondent}

Majority of women 55 percent have married at age group 15-19 years. Similarly, 37 percent of respondents have married at the age 20-24, 7 percent of respondents are married at age $10-14$, only one percent of respondent is married at age 25 and above.

\subsection{Age at first birth and number of living children}

The highest of women 53.8 percent have born their first birth at age group 20-24 and followed by 41.9 percent of respondent age group 15-19 years who carry the high risk for both mother and children and only 4.3 percent born their child at ages $25-29$. This data also presents the numbers of children; most of the respondents (41\%) have two children, followed by 17.2 percent of women who have one and three children, 14.0 percent of respondent have 4 children.

\subsection{Caste and Ethnicity}

The highest of Chhetri caste group of women with 66 percent. Dalit was found in second position with 14 percent and followed by Kirat/ Janajati with 10 percent. Brahman respondents are only the 3 percent.

\subsection{Educational attainment}

Among the literate of 83 respondents, 33.7 percent are non-formal educated. Second position of the secondary level of education of respondent (24.1 percent) and followed by 12 percent of lower secondary education of respondents. Similarly, 2.4 percent of respondents are bachelor and above. The father's educational status, 23.9 percent are gained the secondary level of education, SLC and lower secondary level of education are followed them.

\subsection{Occupation and Income}

More than 30 percent respondents are engaged in the agricultural activities and followed by 28 percent of services. Similarly, 16 percent of respondents are engaged on business and others activities. The first highest income distributions of 20 percent of Rs.1000-2000 and Rs.7000-8000respectively and Followed by 18 percent of respondent's have Rs.3000-4000 of family income in month. Among them 31percent are involved in services, followed 30 percent engaged in agriculture. Similarly, business and others engaged in 16and 15 percent, respectively. 


\subsection{Knowledge of FP}

More than 99 percent of respondent's have knowledge of any methods and one percent respondent have not knowledge of contraceptive method. Among them, pills, injections, male/female sterilization have 100 percent knowledge and 97 percent knowledge of condom, 77 percent knowledge of Norplant's and only 2 percent have knowledge of IUD.

Table 1: Percentage distribution of respondents by level of knowledge and methods

\begin{tabular}{|l|l|l|}
\hline Heard by method & Number & Percent \\
\hline Yes & 99 & 99.0 \\
\hline No & 1 & 1.0 \\
\hline Total & 100 & 100.0 \\
\hline If heard, name of method & Number & Percent \\
\hline Pills & 100 & 100.0 \\
\hline Injections & 100 & 100.0 \\
\hline IUD & 2 & 2.0 \\
\hline Condom & 97 & 97.0 \\
\hline Norplant & 77 & 77.0 \\
\hline Male sterilization & 100 & 100.0 \\
\hline Female sterilization & 100 & 100.0 \\
\hline
\end{tabular}

Source: Field Survey, 2016.

\subsection{Knowledge of FP by age and educational attainment}

Knowledge of family planning varies with educational status of women. The level of knowledge of family planning is found by hundred percent but educational level of only 83 percent. More than 99 percent of currently married women heard at least one modern contraceptive method. The highest knew 47.5 percent of respondent which are age group 25-29 and second 17.2 percent of age group 30-34 respectively and so on. The highest 24.2 secondary level of respondent knew the any method and 19.8 percent followed by SLC and lower secondary level of educated women. 
Table 2: Percentage distribution of respondents by age group and level of education for knowledge

\begin{tabular}{|c|c|c|c|c|c|c|}
\hline \multicolumn{7}{|c|}{ Heard of family planning } \\
\hline \multirow[t]{2}{*}{ Age group } & \multicolumn{2}{|l|}{ Yes } & \multicolumn{2}{|l|}{ No } & \multicolumn{2}{|l|}{ Total } \\
\hline & Number & Percent & Number & Percent & Number & Percent \\
\hline $15-19$ & 1 & 1.0 & 0 & .0 & 1 & 1.0 \\
\hline $20-24$ & 9 & 9.1 & 0 & .0 & 9 & 9.0 \\
\hline $25-29$ & 47 & 47.5 & 1 & 100.0 & 48 & 48.0 \\
\hline $30-34$ & 17 & 17.2 & 0 & .0 & 17 & 17.0 \\
\hline $35-39$ & 15 & 15.2 & 0 & .0 & 15 & 15.0 \\
\hline $40+$ & 10 & 10.1 & 0 & .0 & 10 & 10.0 \\
\hline Total & 99 & 100.0 & 1 & 100. & 100 & 100.0 \\
\hline $\begin{array}{l}\text { Educational } \\
\text { status }\end{array}$ & Number & Percent & Number & Percent & Number & Percent \\
\hline Illiterate & 0 & 0 & 1 & 100.0 & 1 & 1.1 \\
\hline Non-formal & 4 & 4.4 & 0 & .0 & 4 & 4.3 \\
\hline Primary & 12 & 13.2 & 0 & .0 & 12 & 13.0 \\
\hline $\begin{array}{l}\text { Lower } \\
\text { secondary }\end{array}$ & 18 & 19.8 & 0 & .0 & 18 & 19.6 \\
\hline Secondary & 22 & 24.2 & 0 & .0 & 22 & 23.9 \\
\hline S.L.C. & 18 & 19.8 & 0 & .0 & 18 & 19.6 \\
\hline Certificate & 12 & 132 & 0 & .0 & 12 & 13.0 \\
\hline $\begin{array}{l}\text { Bachelor and } \\
\text { above }\end{array}$ & 5 & 5.5 & 0 & .0 & 5 & 5.4 \\
\hline Total & 91 & 100.0 & 1 & 100.0 & 92 & 100.0 \\
\hline
\end{tabular}

Source: Field Survey, 2016.

\subsection{Place of known for family planning}

Above table shows that 99 out of 100 respondent knew hospital and health post 98 percent knew the family planning services. About 93 and 92 percent family planning services knew health worker and family planning clinic. More than 99 percent of respondents out of 100 have heard about the family planning from radio and television. About 85 percent of the respondent have heard about the family planning from friends/neighbor and health worker. 
About 80 and 78 percent of respondents have heard about the family planning from newspaper and husband.

\subsection{Attitude of respondents towards FP and child bearing}

About 76 percent of respondent's replies family planning is good, followed by satisfactory with 17 percent. About 5 percent replies that excellent and only two percent respondents reply bad. The most of women 98 percent replies best childbearing age is above 20 years and only 2 percent of respondents replies best childbearing age is below 20 years.

\subsection{Opinion about advantages of family planning}

Nearly half of the percent of respondents out of 100, replies the advantages of family planning method to make small and happy family and 17 percent of respondents replies to make better education and appropriates.

\subsection{Ever use of Family planning}

More than 90 percent of respondents have used at least one method of family planning and 9 percent of respondents have not used at least one method of family planning. About 37.4 percent of respondents used injections followed by condom with 28.6 percent. Pills are also used by 23 percent of respondents.

Table 3: Percentage distribution of respondents by their view about promotion of family planning

\begin{tabular}{|l|l|l|}
\hline Ever use of family planning method & \multicolumn{1}{|c|}{ Number } & Percent \\
\hline Yes & 91 & 91.0 \\
\hline No & 9 & 9.0 \\
\hline Total & $\mathbf{1 0 0}$ Number & $\mathbf{1 0 0 . 0}$ \\
\hline Method family planning & \multicolumn{1}{|c|}{ Percent } \\
\hline Pills & 21 & 23.1 \\
\hline Injection & 34 & 37.4 \\
\hline IUD & 1 & 1.1 \\
\hline Condom & 26 & 28.6 \\
\hline Norplant & 4 & 4.4 \\
\hline Male sterilization & 3 & 3.3 \\
\hline Female sterilization & 2 & 2.2 \\
\hline Total & $\mathbf{9 1}$ & $\mathbf{1 0 0 . 0}$ \\
\hline
\end{tabular}

Source: Field Survey, 2016. 


\subsection{Number of living children and ever use of family planning methods}

Those women who have one and two children use family planning more than others. The number of children also determines the specific method of family planning the women who have one child use method for birth spacing and women who have two or more than two children use permanent.

Below table shows that 23.8 percent use the pills, among 13.3 percent of respondents have one child, 46.7 percent use injection that have one child, 26.7 percents of women used condom that have one child, 13 percent women used female sterilization that have one child.

Table 4: Percentage Distribution of Respondents Who Have Ever Used any Family Planning method by Number of Live Birth

\begin{tabular}{|c|c|c|c|c|c|c|c|c|c|c|c|c|c|c|}
\hline \multirow[b]{3}{*}{ Methods } & \multicolumn{12}{|c|}{ Number of children ever born } & & \\
\hline & \multicolumn{2}{|l|}{1} & \multicolumn{2}{|l|}{2} & \multicolumn{2}{|l|}{3} & \multicolumn{2}{|l|}{4} & \multicolumn{2}{|l|}{5} & \multicolumn{2}{|l|}{6} & \multicolumn{2}{|c|}{ Total } \\
\hline & $\mathbf{N}$ & $\mathbf{P}$ & $\mathbf{N}$ & $\mathbf{P}$ & $\mathbf{N}$ & $\mathbf{P}$ & $\mathbf{N}$ & $\mathbf{P}$ & $\mathbf{N}$ & $\mathbf{P}$ & $\mathbf{N}$ & $\mathbf{P}$ & $\mathbf{N}$ & $\mathbf{P}$ \\
\hline Pills & 2 & 3.3 & 7 & 20.0 & 5 & 31.2 & 3 & 3.3 & 3 & 50.0 & 0 & 0 & 20 & 23.8 \\
\hline Injection & 7 & 46.7 & 16 & 45.7 & 3 & 8.8 & 2 & 2.2 & 0 & 0 & 2 & 66.7 & 30 & 35.7 \\
\hline IUD & 0 & 0 & 1 & 2.9 & 0 & 0 & 0 & 0 & 0 & 0 & 0 & .0 & 1 & 1.2 \\
\hline Condom & 4 & 26.7 & 8 & 22.9 & 4 & 25.0 & 4 & 44.0 & 3 & 50.0 & 1 & 33.3 & 24 & 28.6 \\
\hline Norplant & 0 & 0 & 3 & 8.6 & 1 & 6.2 & 0 & 0 & 0 & 0 & 0 & 0 & 4 & 4.8 \\
\hline Male sterilization & 0 & 0 & 0 & 0 & 3 & 18.8 & 0 & 0 & 0 & 0 & 0 & 0 & 3 & 3.6 \\
\hline Female sterilization & 2 & 13.3 & 0 & 0 & 0 & 0 & 0 & 0 & 0 & 0 & 0 & 0 & 2 & 2.0 \\
\hline Total & 15 & 100 & 35 & 100 & 16 & 100 & 9 & 100 & 6 & 100 & 3 & 100 & 84 & 100 \\
\hline
\end{tabular}

Source: Field survey, 2016.

\subsection{Reason for using family planning among ever users}

The various method of family planning is available. The respondents use the specific method of family planning. More than 37 percent if ever used respondents use specific method for easy to obtain, followed by 28 percent respondents use this method for no side effect. About 23 percent use this method for effective methods and around 10 percent use this method for recommendation by health worker. 
Table 5: Percentage Distribution of Respondents’ of Family Planning Methods Ever Users by Reasons for Use

\begin{tabular}{|l|l|l|l|}
\hline \multirow{2}{*}{ Reason for use } & Number & & Percent \\
\hline Easy to obtain & 34 & & 37.4 \\
\hline Effective Method & 21 & & 23.1 \\
\hline No side effect & 27 & & 29.7 \\
\hline Recommendation by health worker & 9 & & 9.9 \\
\hline Total & $\mathbf{9 1}$ & & $\mathbf{1 0 0 . 0}$ \\
\hline
\end{tabular}

Source: Field Survey, 2016.

\subsection{Current use of FP}

The contraceptive prevalence rate is found to be 92 percent among currently married women of reproductive age group 15-49 years. The contraceptive prevalence rate is higher than the national level. The injection is used by 51.3 percents and it is mostly used method. This is followed by female sterilization with 42.4 percent. About 3.3 and 2.2 used pills and condom.

Table 6: percentage distribution of ever user by reasons

\begin{tabular}{|l|l|l|}
\hline Methods & Number of respondent & Percent \\
\hline Pills & 3 & 3.3 \\
\hline Injection & 47 & 51.1 \\
\hline Condom & 1 & 1.1 \\
\hline Norplant & 2 & 2.2 \\
\hline Female sterilization & 39 & 42.4 \\
\hline Total & $\mathbf{9 2}$ & $\mathbf{1 0 0 . 0}$ \\
\hline
\end{tabular}

Source: Field survey, 2016

\subsection{Age of women and current use of FP}

The table present below provides the distribution of currently married women who are currently using family planning method by method and age. The use of family planning 
higher 87.5 percent of injection with age group 20-24 years, followed by age group 25-29, 30-34, 35-39 age group with 60, 41.2, 42.9 percent respectively. Similarly, so on.

Table 7: Percentage Distribution of Respondents' Who Are Currently Using Family Planning Methods by Reasons Methods and Age

\begin{tabular}{|c|c|c|c|c|c|c|c|c|c|c|c|c|}
\hline \multirow{3}{*}{$\begin{array}{l}\text { Current use } \\
\text { Method }\end{array}$} & \multicolumn{10}{|c|}{ Age group of respondent } & & \\
\hline & \multicolumn{2}{|c|}{$20-24$} & \multicolumn{2}{|c|}{$25-29$} & \multicolumn{2}{|c|}{$30-34$} & \multicolumn{2}{|c|}{$35-39$} & \multicolumn{2}{|c|}{$40+$} & \multicolumn{2}{|c|}{ Total } \\
\hline & $\mathrm{N}$ & $\mathrm{P}$ & $\mathrm{N}$ & $\mathrm{P}$ & $\mathrm{N}$ & $\mathrm{P}$ & $\mathrm{N}$ & $\mathrm{P}$ & $\mathrm{N}$ & $\mathrm{P}$ & $\mathrm{N}$ & $\mathrm{P}$ \\
\hline Pills & 0 & 0 & 1 & 2.2 & 1 & 5.9 & 1 & 7.1 & 0 & 0 & 3 & 3.3 \\
\hline Injection & 7 & 87.5 & 27 & 60.0 & 7 & 41.2 & 6 & 42.9 & 0 & 0 & 47 & 51.1 \\
\hline Condom & 1 & 12.5 & 0 & .0 & 0 & 0 & 0 & 0 & 0 & 0 & 1 & 1.1 \\
\hline Norplant & 0 & 0 & 2 & 4.4 & 0 & 0 & 0 & 0 & 0 & 0 & 2 & 2.2 \\
\hline $\begin{array}{l}\text { Female } \\
\text { sterilization }\end{array}$ & 0 & 0 & 15 & 33.3 & 9 & 52.9 & 7 & 50.0 & 8 & 100.0 & 39 & 42.4 \\
\hline Total & 8 & 100.0 & 45 & 100.0 & 17 & 100.0 & 14 & 100.0 & 8 & 100.0 & 92 & 100.0 \\
\hline
\end{tabular}

Source: Field Survey, 2016.

\subsection{Education of women and current use of FP}

Education of the women directly related with use of family planning. The choice of methods also varies with educational attainment. The three respondents are use of pills that are only SLC level of education. Among the 42 respondents current use of injections, but highest use of injections 11 respondents who are non-formal education. Female sterilization is 30 respondents

\subsection{Reason for current use and non- use of FP}

Among the 100 respondents, 92 are currently using family planning. About 8 respondents are not currently use of family planning methods. 39 percent of the respondents use the specific method for effective method and followed by 23.9 percent of respondents using for easy to obtain.

\section{Conclusion}

During the last decade, substantial development in infromation, education and communication has been made in Nepal. On the basis of result obtain from the study; the level of family planning knowledge among currently married women of reproductive age 
group 15-49 is 100 percent. The knowledge of family planning is national level. Most of the respondent's concept about family planning method is found to be positive. The main reason for using family planning is to space birth and stop child bearing. The main reason for non using family planning is desire for children and husband and family disagreement.

There is positive relationship observed between use of family planning and educational attainment of women. The heard of family planning is increased with the level of education. Nowadays also women shy to discuss about family planning, which is an obstacle in the way of providing knowledge about family planning. Health post and health centre are the main suppliers of contraceptive method. Injection, pills, condom and sterilization are widely used method of family planning.

\section{References}

CBS, (2011). "National Population and Housing Census." Central Bureau of Statistic HMG, Kathmandu, Nepal

Ministry of Health and Population, (2001). "Nepal Demographic Health Survey" Maryland USA, Family Health Division, Ministry of Health, New Era and ORC Macro PP. 139-169.

Ministry of Health and Population, (2006). 'Nepal Demographic and Health Survey.' Kathmandu, Nepal: Ministry of Health and Population, New ERA, and Macro International Inc., Calverton, Maryland, USA.

Ministry of Health and Population, (2011). 'Nepal Demographic and Health Survey.' Kathmandu, Nepal: Ministry of Health and Population, New ERA, and Macro International Inc., Calverton, Maryland, USA.

Ministry of Health and Population, (2016). 'Nepal Demographic and Health Survey.' Kathmandu, Nepal: Ministry of Health and Population, New ERA, and Macro International Inc., Calverton, Maryland, USA.

World Health Organization (WHO), (2010). Population Bulletin, 2010. Kathmandu: WHO 